\title{
Intensive neuromotor therapy with suit improves motor gross function in cerebral palsy: a Brazilian study
}

\author{
Tainá Ribas Mélo1,2, Bruna Yamaguchi¹, Claudiana Renata Chiarello³, Ana Cláudia Szczypior \\ Costin $^{2,3}$, Vanessa Erthal ${ }^{2}$, Vera Lúcia Israel ${ }^{1}$, Eduardo Borba Neves ${ }^{4 *}$

\begin{abstract}
Cerebral palsy (CP) is the most common disability in children caused by central nervous system lesion. The aim of the present study was to verify the intensive neuromotor therapy effects in children with $\mathrm{CP}$, in a reference Brazilian centre. In this study, three years of medical records from a Brazilian reference Centre of Intensive Neuromotor Therapy (INMT) which use the INMT protocol were analysed. The motor evaluation for each child was done by the Gross Motor Function Classification System (GMFCS) and GMFM- 88 by an experienced professional, before and after each INMT module. A total of 53 children between the ages of 1 and 15 years (age at treatment initiation, initial evaluation), with a mean age of $5.94 \pm 3.38$ years, participated in the study. Participants performed between 1 and 10 INMT modules. There was no strong correlation between age and overall performance on the GMFM scale, but it was observed a strong negative correlation between the percentage of GMFM gains and the number of modules $\left(r=-0.709 ; R^{2}=0.50 ; p=\right.$ 0.022 , CI95\%[0.014 - 0.026]), suggesting that patients tend to present higher percentage gains in the first modules. Through an intra-module comparison, it was observed statistical difference in the total score in each of the modules.
\end{abstract}

Keywords: Cerebral palsy, Treatment, Physical Therapy, Pediasuit

\section{INTRODUCTION}

Cerebral palsy $(\mathrm{CP})$ is the most common disability in children caused by central nervous system lesion (Morgan, Novak, Dale, Guzzetta, \& Badawi, 2014). Actually, there is a paradigm for the better management for physical therapy of $\mathrm{CP}$ approaches to a more focused and intense active training protocol, although the benefits of fairly intense physical exercise programs need to be better recognized (Damiano, 2006).

A success of a therapy can be defined as one that can provide changes in activities and participation by the ICF (International Classification of Functioning, Disability and Health) model and best quality of life whom receive that (Damiano, 2009; Gannotti, Christy, Heathcock, \& Kolobe, 2014)

For $\mathrm{CP}$, there is minimal evidence for the neurodevelopmental therapy. However, evidence for the best outcomes were for intensive training and practice task or functionally (Bailes et al., 2011; Bailes, Greve, \& Schmitt, 2010; Damiano, 2009). The effects of intervention intensity are still controversial, showing for example that the effects of four weeks of home physical therapy were greater than those of 8 weeks (Hwang, Chao, \& Liu, 2013), until this moment there is no evidence that greater intensity ensures better results (DeLuca, Case-Smith, Stevenson, \& Ramey, 2012).

Other therapies like Adeli ${ }^{\mathrm{TM}}$ and Conductive Education need more researches to explain the multiple components of these therapies that could provide some results (Damiano, 2009). Adeli $^{\mathrm{TM}}$ Suit (Shvarkov, Davydov, Kuuz, Aipova, $\&$ Vein, 1997) and Thera ${ }^{\mathrm{TM}}$ suit (Bailes et al., 2010) have their origins in Russian. In Brazil, the Pediasuit $^{\mathrm{TM}}$ method (Scheeren et al., 2012) has

\footnotetext{
Manuscript received at April 15 $5^{\text {th }} 2017$; Accepted at October $7^{\text {th }} 2017$

${ }^{1}$ Federal University of Paraná, Curitiba, Paraná, Brazil

${ }^{2}$ University Center Campos de Andrade, Curitiba, Paraná, Brazil

${ }^{3}$ Vitória Research Center, Curitiba, Paraná, Brazil

${ }^{4}$ Federal Technological University of Paraná (UTFPR), Curitiba, Paraná, Brazil

* Corresponding author: Av. Sete de Setembro, 3165 - Rebouças, CEP 80230-901, Curitiba, Paraná, Brazil. E-mail: neveseb@gmail.com
} 
been recently used in combination with other methods (Thera suit, neurodevelopmental treatment) in an intensive training protocol called Intensive Neuromotor Therapy (Neves, Scheeren, Chiarello, Costin, \& Mascarenhas, 2012). All of these are intensive training physical therapy with suits, but intensive training could include therapies without them. Recent systematic review (Castilho-Weinert \& Neves, 2016; Martins et al., 2015) indicates that while some studies reported improvement in gross motor skills, the benefits of intensive physical therapy programs with dynamic clothes need more investigation.

Intensive training with infants is done one hour once a week (Blauw-Hospers \& HaddersAlgra, 2005) without a suit. For toddlers and children, intensive training is 3-4 hours a day, 5 times a week (Bailes, Greve, Burch, Reder, \& Huth, 2008; Bar-Haim et al., 2006; Carr, Kolobe, O'Connell, \& Sammy, 2006; Christy, Saleem, Turner, \& Wilson, 2010) for a period of 3 or 4 weeks (Sorsdahl, Moe-Nilssen, Kaale, Rieber, \& Strand, 2010) interspersed with rest or conventional physical therapy periods (Christy et al., 2010).

In general, studies with intensive protocols for $\mathrm{CP}$ are contradictory: some of them with improvement on Gross Motor Function in CP (Bailes et al., 2010; Bower, McLellan, Arney, \& Campbell, 1996; Carr et al., 2006; Christy et al., 2010; Neves et al., 2013; Neves et al., 2012; Shvarkov et al., 1997) and quality of life (Dilenno \& Atkinson, 2006), and another without improvements (Bailes et al., 2011; Bailes et al., 2008).

Furthermore, the efficiency of these therapies need to be considered due to cost and time of daily therapy (Damiano, 2009). In the USA this cost could be 10 thousand dollars (Christy et al., 2010). In Brazil this value it is almost 3 thousand dollars by module, which is expensive for a poor country.

The aim of the present study was, therefore, to verify the intensive neuromotor therapy effects in children with $\mathrm{CP}$, in a reference Brazilian centre.

\section{METHOD}

This is a retrospective study approved by Ethics Committee of Brazilian Institute of Therapies and Teaching CAAE: 53310116.8.0000.5229, with Brazilian clinical registration RBR-2st594.

\section{Sample}

In this study medical records from a Brazilian reference Centre which use the INMT protocol, registered from 2013 until 2015, were analysed.

This protocol included PediaSuit ${ }^{\mathrm{TM}}$ (Scheeren et al., 2012) worn with ludic therapy in an enrichment environment (Morgan et al., 2014). From these 53 medical records of Brazilian children with cerebral palsy who received INMT were included. Children with $\mathrm{CP}$ associated with another conditions and syndromes were excluded.

\section{Procedures}

The motor evaluation for each child was done by the Gross Motor Function Classification System (GMFCS) and GMFM-88 by an experienced professional, before and after each INMT module. The GMFM consists of 88 items grouped into 5 dimensions: (A) lying and rolling, (B) sitting, (C) crawling and kneeling, (D) standing and (E) walking, running, and jumping (Palisano et al., 2000; Rosenbaum et al., 2002; Russell et al., 1989). In this evaluation there are scores for each dimension, a partial score that verifies the goal areas, and a total score. This evaluation permits measurement of activities and participation (Sposito \& Riberto, 2010) considering ICF assumptions (Schiariti et al., 2014; Schiariti \& Mâsse, 2014; Schiariti, Selb, Cieza, \& O'Donnell, 2015).

The children were accompanied by up to 10 modules. Each module consists of 3-4 hours a day, 5 times a week, for a period of 4 weeks with a total of $60-80$ hours of exercise by module. The intervention is priority physical therapy exercises with additional intervention of multidisciplinary professionals, including occupational therapy and speech therapy. Each day of therapy included a break time of 15 minutes for lunch, restroom, and/or rest. 
The physical therapy exercises include warmup and stretching, suit, "monkey cage" and "spider cage", all exercises done for each functional child possibility. A description of this intervention can be found in Scheeren et al. (Scheeren et al., 2012).

\section{Statistical analysis:}

After presenting the descriptive measures, we used a statistical package (IBM SPSS-22, USA) to perform normality data and non-parametric Wilcoxon statistical tests, for comparison before and after each INMT module, as well as Spearman correlation test (rs), between the mean of the total of GMFM gain (score difference) with the number of modules, overall GMFM average with age.

\section{RESULTS}

A total of 53 children between the ages of 1 and 15 years (age at treatment initiation, initial evaluation), with a mean age of $5.94 \pm 3.38$ years, participated in the study. Participants performed between 1 and 10 INMT modules.

Most of them (Table 1) with severe motor impairments GMFCS V (43.4\%), quadriplegia (39.62\%) and diplegia (35.85\%) and are younger $(77.36 \%)$ than 7 years. How it a retrospective study with medical records analysis some descriptive information was not found, identified in this study with not defined.

Of these 53 children, 43 completed 2 modules. The number of children decreased as the number of modules increased (Table 2).

There was no strong correlation between age and overall performance on the GMFM scale, but it was observed a strong negative correlation between the percentage of GMFM gains and the number of modules, with correlation coefficient $0.709\left(r^{2}=0.50\right), p=0.022$, with CI95\%[0.0140.026], demonstrating, associated with the comparison by modules, that patients tend to present higher percentage gains in the first modules, but intra-module comparison shows statistical difference in the total score in each of the modules.

Table 1

Sample characterization

\begin{tabular}{lcc}
\hline Topographic classification & $\mathrm{n}$ & $\%$ \\
\hline Quadriplegia & 21 & 39.62 \\
Diplegia & 19 & 35.85 \\
Hemiplegia & 3 & 5.66 \\
Dystonia & 2 & 3.77 \\
Ataxia & 1 & 1.89 \\
Not defined & 7 & 13.21 \\
& 53 & 100 \\
GMFCS level & & \\
I & 3 & 5.66 \\
II & 3 & 5.66 \\
III & 5 & 9.43 \\
IV & 10 & 18.87 \\
V & 23 & 43.40 \\
Not defined & 9 & 16.98 \\
& 53 & 100 \\
Age distribution (years) & & \\
$<7$ years & 43 & 81.13 \\
$>7$ years & 10 & 18.87 \\
& 53 & 100 \\
\hline
\end{tabular}

Not defined $=$ not found or not informed

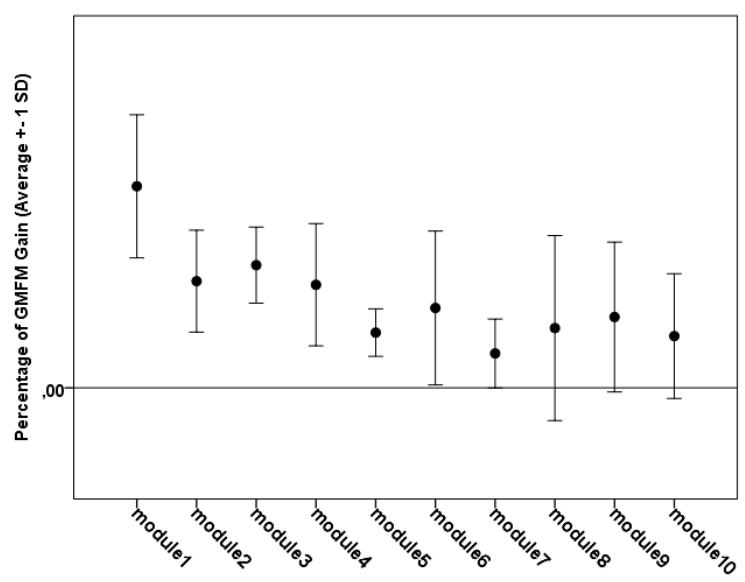

Figure 1. Percentage of GMFM gain in each module

There was a significant difference in most of the modules and almost all dimensions of GMFM, except for module 6 for all scores and module 7 for the dimensions scores. 
Table 2

GMFM score in each module

\begin{tabular}{|c|c|c|c|c|c|c|c|c|c|c|}
\hline \multirow{3}{*}{$\begin{array}{l}\sum_{0}^{\infty} \\
\sum_{0}^{\infty} \\
\sum_{0}^{\infty}\end{array}$} & \multicolumn{10}{|c|}{$\begin{array}{c}\text { Median 50\% } \\
25-75 \%\end{array}$} \\
\hline & Module 1 & Module 2 & Module 3 & Module 4 & Module 5 & Module 6 & Module 7 & Module 8 & Module 9 & Module 10 \\
\hline & $\mathrm{n}=53$ & $\mathrm{n}=43$ & $\mathrm{n}=39$ & $\mathrm{n}=30$ & $\mathrm{n}=24$ & $\mathrm{n}=16$ & $\mathrm{n}=15$ & $\mathrm{n}=10$ & $\mathrm{n}=7$ & $\mathrm{n}=6$ \\
\hline & : $55.88 \%$ & $77.45 \%$ & $73.52 \%$ & $73.52 \%$ & $82.35 \%$ & $75.54 \%$ & $75.49 \%$ & $81.37 \%$ & $69.60 \%$ & 73.52 \\
\hline & à $49.01-82.35 \%$ & $68.62-86.27 \%$ & $63.23-83.82 \%$ & $65.68-82.35 \%$ & $50-89.70 \%$ & $47.05-100 \%$ & $51.47-86.76 \%$ & $50-88.23 \%$ & $59.80-86.76 \%$ & $57.35-83.82 \%$ \\
\hline & $\overrightarrow{0} \quad 74.50 \%$ & $84.31 \%$ & $81.37 \%$ & $82.35 \%$ & $87.25 \%$ & $74.50 \%$ & $75.49 \%$ & $83.33 \%$ & $72.54 \%$ & $77.45 \%$ \\
\hline & م. $70.09-88.23 \%$ & $79.90-88.23 \%$ & $71.56-91.17 \%$ & 75.49-91.17\% & $52.45-91.17 \%$ & $54.90-100 \%$ & $58.82-86.76 \%$ & $61.76-92.64 \%$ & $61.27-86.76 \%$ & $59.80-85.29 \%$ \\
\hline & $\cong \quad 19.16 \%$ & $23.33 \%$ & $19.16 \%$ & $22.50 \%$ & $20 \%$ & $35.50 \%$ & $20 \%$ & $21.66^{\circ}$ & $19.16 \%$ & 15 \\
\hline & â. $15.00-38.33 \%$ & $19.16-40.41 \%$ & $16.66-41.66 \%$ & $17.91-44.16 \%$ & $15-40 \%$ & $17.50-89.16 \%$ & $15-40 \%$ & $18.75-41.25 \%$ & $15-38$ & $15-40$ \\
\hline & $\overrightarrow{2} \quad 22.50 \%$ & $25 \% \%$ & $26.66 \%$ & $24.16 \%$ & $23.33 \%$ & $33.33 \%$ & $20.83 \%$ & $25 \%$ & 23.33 & $15 \%$ \\
\hline & . $17.50-41$. & $24.58-43.33 \%$ & $22.50-45.41 \%$ & $19.58-4 \varepsilon$ & $15-42.50 \%$ & $20-90 \%$ & $18.75-41.66 \%$ & $18.75-46.25 \%$ & $15-42$ & $15-41.66 \%$ \\
\hline & $\because \quad 0.00 \%$ & $02.38 \%$ & $0.00 \%$ & $0.00 \%$ & $11.90 \%$ & $1.19 \%$ & $0.00 \%$ & $0.00 \%$ & $0.00 \%$ & $0.00 \%$ \\
\hline & ¿ $\quad 0.00-9.52 \%$ & $0.00-16.66 \%$ & $0.00-22.61 \%$ & $0.00-20.83 \%$ & $0.00-20.23 \%$ & $0.00-76.19 \%$ & $0.00-24.40 \%$ & $0.00-24.40 \%$ & $0.00-20.23 \%$ & $0.00-22.61 \%$ \\
\hline & $2.38 \%$ & $2.38 \%$ & $1.19 \%$ & $1.19 \%$ & $2.38 \%$ & 2.381 & 0.0 & 1.19 & & \\
\hline & ฉ. $0.00-16.66 \%$ & $0.00-19.64 \%$ & $0.00-25.59 \%$ & $0.00-25 \%$ & $0.00-22.61 \%$ & $0.00-77.38 \%$ & $0.00-24.40 \%$ & $0.00-24.40 \%$ & $0.00-27$. & $0.00-23$ \\
\hline & $\cong \quad 0.00 \%$ & $0.00 \%$ & $0.00 \%$ & $0.00^{\circ}$ & $0.00 \%$ & $0.00^{\circ}$ & $0.00 \%$ & 0.00 & 0.00 & 0.00 \\
\hline & 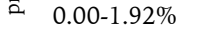 & $0.00-01.92 \%$ & $0.00-2.56 \%$ & $0.00-3.84 \%$ & $0.00-12.82 \%$ & $0.00-12.82 \%$ & $0.00-4.48 \%$ & $0.00-2.56 \%$ & $0.00-5.76 \%$ & $0.00-22.61 \%$ \\
\hline & $\begin{array}{l}\overrightarrow{\mathrm{H}} \\
0\end{array} \quad 0.00 \%$ & $0.00 \%$ & $0.00 \%$ & $0.00 \%$ & $0.00 \%$ & $0.00 \%$ & $0.00 \%$ & $0.00 \%$ & 0.00 & 0.00 \\
\hline & ฉ. $\quad 0.00-25.64 \%$ & $0.00-19.64 \%$ & $0.00-3.20 \%$ & $0.00-$ & $0.00-1.28 \%$ & $0.00-12.82 \%$ & $0.00-4.48 \%$ & $0.00-2$ & $0.00-7.69 \%$ & $0.00-5.76 \%$ \\
\hline & $\stackrel{0.00 \%}{0}$ & $0.00 \%$ & $0.00 \%$ & $0.00 \%$ & $0.00 \%$ & $0.00 \%$ & $0.00 \%$ & $0.00 \%$ & 0.00 & $0.0 c$ \\
\hline & z. $\quad 0.00-0.00 \%$ & $0.00-10.41 \%$ & $0.00-1.38 \%$ & $0.0000-1.04 \%$ & $0.00-1.73 \%$ & $0.00-04.86 \%$ & $0.00-1.04 \%$ & $0.00-1.04 \%$ & $0.00 \%-0.00 \%$ & $0.00 \%-0.00 \%$ \\
\hline & $\begin{array}{l}\vec{w} \\
0.00 \%\end{array}$ & $0.00 \%$ & $0.00 \%$ & $0.00 \%$ & $0.00 \%$ & $0.00 \%$ & $0.00 \%$ & $0.00 \%$ & $0.00 \%$ & $0.00 \%$ \\
\hline & ב. $\quad 0.00-0.00 \%$ & $0.00-1.04 \%$ & $0.00-1.38 \%$ & $0.00-2.77 \%$ & $0.00-1.73 \%$ & $0.00-4.86 \%$ & & & $0.00 \%-0.00 \%$ & $0.00 \%-0.00 \%$ \\
\hline \multirow{4}{*}{ वै } & $\cong \quad 35.85 \%$ & $43.85 \%$ & $46.56 \%$ & & $36.13 \%$ & $43.00 \%$ & & & & \\
\hline & ? $27.44-42.81 \%$ & $36.17-48.95 \%$ & $38.39-51.49 \%$ & $39.31-50.07 \%$ & 31.71-54.54\% & $31.29-56.60 \%$ & $34.39-52.06 \%$ & $34.39-53.14 \%$ & $38.65-54.47 \%$ & $32.16-50.66 \%$ \\
\hline & $40.78 \%$ & $50.83 \%$ & $51.51 \%$ & $47.81 \%$ & $36.43 \%$ & $42.51 \%$ & $45 \%$ & $45.36 \%$ & $46.47 \%$ & $44.87 \%$ \\
\hline & $29.85-52.61 \%$ & 37.94-54.32\% & $35.66-57.77 \%$ & 41.24-54.65\% & $32.14-55.85 \%$ & $34.72-57.01 \%$ & $35.13-52.14 \%$ & $34.39-53.14 \%$ & $33.63-56.24 \%$ & $32.65-54.11 \%$ \\
\hline \multirow{4}{*}{$\stackrel{\circ}{+}$} & $\cong \quad 15.11 \%$ & $19.69 \%$ & $18.62 \%$ & $18.90 \%$ & $20.11 \%$ & $21.09 \%$ & $18.59 \%$ & $20.80 \%$ & $18.08 \%$ & $17.70 \%$ \\
\hline & ב $13.39-25.67 \%$ & $18.46-29.26 \%$ & $16.68-29.17 \%$ & $17.30-30.15 \%$ & $14.25-30.23 \%$ & $13.01-56.60 \%$ & $14.54-30.83 \%$ & $14.50-30.45 \%$ & $15.46-29.22 \%$ & $15.72-28.76 \%$ \\
\hline & 若 $\quad 20.14 \%$ & $22.47 \%$ & $22.14 \%$ & $21.14 \%$ & & $24.14 \%$ & & & & 18.68 \\
\hline & a. $17.63-28.99^{\circ}$ & $21.02-30.33 \%$ & $19.09-32.05 \%$ & $19.60-33.84 \%$ & $15.40-30.86 \%$ & $14.98-57.01 \%$ & $16.26-30.92 \%$ & $17.60-32.66 \%$ & $-31.40^{\circ}$ & $16.21-29.76$ \\
\hline
\end{tabular}

A-lying and rolling; B-sitting; C-crawling and kneeling; D-standing; E- walking. running. and jumping

Table 3

GMFM scores difference

\begin{tabular}{|c|c|c|c|c|c|c|c|c|c|c|}
\hline \multirow{2}{*}{$\sum_{j=}^{\sum_{j}^{\infty}}$} & \multicolumn{10}{|c|}{$\begin{array}{c}\text { Difference }(Z) \\
P\end{array}$} \\
\hline & $\mathrm{n}=53$ & $\mathrm{n}=43$ & $\mathrm{n}=39$ & $\mathrm{n}=30$ & $\mathrm{n}=24$ & $\mathrm{n}=16$ & $\mathrm{n}=15$ & $\mathrm{n}=10$ & $\mathrm{n}=7$ & $\mathrm{n}=6$ \\
\hline A & $\begin{array}{l}-5.449 \% \\
p<0.001\end{array}$ & & & $\begin{array}{c}-3.411 \% \\
p=0.01\end{array}$ & $\begin{array}{l}-3.066 \% \\
p=0.02\end{array}$ & $\begin{array}{l}-2.375 \% \\
p=0.018\end{array}$ & $\begin{array}{l}-1.185 \% \\
p=0.236\end{array}$ & $\begin{array}{l}-2.023 \% \\
p=0.043\end{array}$ & $\begin{array}{l}-2.201 \% \\
p=0.028\end{array}$ & $\begin{array}{l}-1.841 \% \\
p=0.066\end{array}$ \\
\hline B & $\begin{array}{l}-5.593 \% \\
p<0.001\end{array}$ & & $\begin{array}{l}-4.399 \% \\
p<0.001\end{array}$ & $\begin{array}{c}-3.307 \% \\
p=0.01\end{array}$ & $\begin{array}{c}-3.301 \% \\
p=0.01\end{array}$ & $\begin{array}{l}-1.826 \% \\
p=0.068\end{array}$ & $\begin{array}{l}-1.367 \% \\
p=0.172\end{array}$ & $\begin{array}{l}-2.023 \% \\
p=0.043\end{array}$ & $\begin{array}{l}-2.032 \% \\
p=0.042\end{array}$ & $\begin{array}{l}-1.000 \% \\
p=0.317\end{array}$ \\
\hline C & $\begin{array}{l}-4.219 \% \\
p<0.001\end{array}$ & & $\begin{array}{l}-3.083 \% \\
p=0.002\end{array}$ & $\begin{array}{l}-3.215 \% \\
p=0.001\end{array}$ & $\begin{array}{l}-2.911 \% \\
p=0.004\end{array}$ & $\begin{array}{l}-1.604 \% \\
p=0.109\end{array}$ & $\begin{array}{l}-0.368 \% \\
p=0.713\end{array}$ & $\begin{array}{l}-1.826 \% \\
p=0.068\end{array}$ & $\begin{array}{l}-1.604 \% \\
p=0.109\end{array}$ & $\begin{array}{l}-1.000 \% \\
p=0.317\end{array}$ \\
\hline D & $\begin{array}{l}-3.735 \% \\
p<0.001\end{array}$ & & $\begin{array}{l}-2.530 \% \\
p=0.011\end{array}$ & $\begin{array}{l}-1.450 \% \\
p=0.147\end{array}$ & $\begin{array}{l}-1.890 \% \\
p=0.059\end{array}$ & $\begin{array}{l}-1.342 \% \\
p=0.180\end{array}$ & $\begin{array}{l}-1.826 \% \\
p=0.068\end{array}$ & $\begin{array}{l}-1.342 \% \\
p=0.180\end{array}$ & $\begin{array}{l}-1.000 \% \\
p=0.317\end{array}$ & $\begin{array}{l}-1.000 \% \\
p=0.317\end{array}$ \\
\hline E & $\begin{array}{l}-2.805 \% \\
p=0.005\end{array}$ & $\begin{array}{l}-2.120 \% \\
p=0.034\end{array}$ & $\begin{array}{l}-1.633 \% \\
p=0.102\end{array}$ & $\begin{array}{l}-2.214 \% \\
p=0.027\end{array}$ & $\begin{array}{l}-1.604 \% \\
p=0.109\end{array}$ & $\begin{array}{l}-1.414 \% \\
p=0.157\end{array}$ & $\begin{array}{l}-1.342 \% \\
p=0.180\end{array}$ & $\begin{array}{l}-1.000 \% \\
p=0.317\end{array}$ & $\begin{array}{c}0.000 \% \\
p=1.000\end{array}$ & $\begin{array}{c}0.000 \% \\
p=1.000\end{array}$ \\
\hline Partial Score & $\begin{array}{l}-4.677 \% \\
p<0.001\end{array}$ & $\begin{array}{l}-3.236 \% \\
p=0.001\end{array}$ & $\begin{array}{l}-3.886 \% \\
p<0.001\end{array}$ & $\begin{array}{l}-3.162 \% \\
p=0.002\end{array}$ & $\begin{array}{l}-2.728 \% \\
p=0.006\end{array}$ & $\begin{array}{l}-1.785 \% \\
p=0.074\end{array}$ & $\begin{array}{l}-2.510 \% \\
p=0.012\end{array}$ & $\begin{array}{l}-0.943 \% \\
p=0.346\end{array}$ & $\begin{array}{l}-0.943 \% \\
p=0.346\end{array}$ & $\begin{array}{l}-2.032 \% \\
p=0.042\end{array}$ \\
\hline Total & $\begin{array}{l}-6.215 \% \\
p<0.001\end{array}$ & $\begin{array}{l}-5.232 \% \\
p<0.001\end{array}$ & $\begin{array}{l}-5.012 \% \\
p<0.001\end{array}$ & $\begin{array}{l}-4.458 \% \\
p<0.001\end{array}$ & $\begin{array}{l}-4.015 \% \\
p<0.001\end{array}$ & $\begin{array}{l}-2.805 \% \\
p=0.005\end{array}$ & $\begin{array}{l}-3.059 \% \\
p=0.002\end{array}$ & $\begin{array}{l}-2.201 \% \\
p=0.028\end{array}$ & $\begin{array}{l}-2.101 \% \\
p=0.028\end{array}$ & $\begin{array}{l}-2.032 \% \\
p=0.042\end{array}$ \\
\hline
\end{tabular}

A-lying and rolling; B-sitting; C-crawling and kneeling; D-standing; E- walking. running. and jumping 


\section{DISCUSSION}

The descriptive characterization of the sample confirms that families seeking for INMT therapy have children with severe motor impairment (GMFCS V, spastic quadriplegia). In such cases, their motor skills are concentrated in the dimensions lying down and rolling, sitting down.

Participants performed between 1 and 10 INMT modules and differences were found in almost all of them in all dimensions. There was a negative correlation between the overall GMFM performance and the ordinal number of the modules. It means that patients tend to present higher percentage gains in the first modules. The intra-module comparison shows statistical difference in the total score in each of the modules. It is interesting to note that gains were obtained in almost all modules, even in children with severe impairments.

These results confirm the positive effects of INMT and may reflect the effect of age in possibilities of motor gains. In the first module, smaller and younger children had better outcomes for motor improvements. The same explanation could be used when statistical differences were found between pre- and posttest in the modules, considering majority of sample is younger than 7 years and that previous studies identified stability of motor performance from this age (Hanna, Bartlett, Rivard, \& Russell, 2008; Hanna et al., 2009).

Beyond the question of age, the better performance in first module could be explained in that the INMT could represent different stimulus for children in their first contact and from the second onwards, a learning effect associated with the maximum expected motor potential (Hanna et al., 2009) may make difficult the larger effects, although they have, nevertheless, been significant in all modules when considering total scores.

There was no strong correlation between age and overall performance on the GMFM scale, and it represents a good finding, considering the stability and loss of function expected in adolescent for children with GMFCS IV and V (Hanna et al., 2009) and generally children with GMFCS I and II present better responses to interventions (Christiansen \& Lange, 2008), considering that in this study the majority of these sample was GMFCS IV and V. Maybe these results could be better with GMFCS I and II but considering that theses patient have independent gait, less interest in INMT therapy is expected for these patients, given the financial and organizational expenditure of the family with intensive interventions.

Comparing with other studies, improvements in motor function were found in children with diplegia (Alagesan \& Shetty, 2011; Neves et al., 2012), little gains in dimension $D$ and $E$ of GMFM on diplegic children (Bailes et al., 2010); but another study didn't find differences compared traditional physical therapy (Bar-Haim et al., 2006).

The effect observed in dimension $\mathrm{A}$ and $\mathrm{B}$ reflect stimulus provided by the Pediasuit ${ }^{\mathrm{TM}}$ that serves as a stability vest in alignment that produces a vertically load of 15 to $40 \mathrm{~kg}$, permits trunk control in vertical position and is used in a diversity of fun and functional exercises. Additional strength, stretch and balance exercises in the ability exercise unity (spider and monkey cage) and bungee cords enables different movements (Scheeren et al., 2012) that would not be possible on an active form for some children with severe impairments, and this way could have these experiences improving their abilities reflected on GMFM scores. The bungee cords also permits adjustment, security and resistance in exercises (Scheeren et al., 2012).

Children with CP normally present deficiency in the processing of sensory information, in this sense, proprioceptive, tactile and visual stimulus need to be trained as part of sensory integration to promote better movement control (Brasileiro \& Moreira, 2008).

INMT give sensorial benefits through cutaneous stimulation with light brushing of the skin (Scheeren et al., 2012) which can provide a neural adaptation (Krueger-Beck et al., 2011) and facilitate the emergence of functional movements. Sensorial, specific vestibular stimulus (Myrhaug, Østensjø, Larun, OdgaardJensen, \& Jahnsen, 2014) also are done in suspension and balance exercise and can help to minimize the effects of pathological reflexes, 
especially those caused by the position of the head, considering that majority of the patients of this sample are quadriplegic children.

It is noticed that children with disabilities require many more repetitions for learning the same task when compared to children with typical development (Scheeren et al., 2012). Thus, the intensive exercise justifies more intensive intervention approaches. In addition, strength and muscular endurance are required.

Resistance exercise are beneficial for children with CP (Eek \& Beckung, 2008) improving motor abilities, but there seems to be a trend in training 2-3 (Damiano, Quinlivan, Owen, Shaffrey, \& Abel, 2001) up to 5 times a week (Ahl, Johansson, Granat, \& Carlberg, 2005) and this evidence is confirmed in the present study performed with localized as well as global and task-oriented exercises.

A recent review (Myrhaug et al., 2014) suggests that rehabilitation of intensive training for a shorter period including practicing in the child's natural environment may be more effective for learning functional skills, because of this, the reference centre where the study was carried out performs daily activities according to the assumptions of ICF.

In addition to the effects mentioned and investigated, functional maintenance can prevent shortening (Alagesan \& Shetty, 2011), deformities, atrophy and loss of bone mass which are common complications in these children, especially those with greater motor impairment (Unay et al., 2003). It is suggested the addition of monitoring of body composition parameters of children with CP (Neves et al., 2014; Neves, 2013). Regarding to the limitations of this study, it can be cited the lack of control group without intervention, but in studies of children with $\mathrm{CP}$, it is an ethics impossibility considering their severe impairments.

\section{CONCLUSION}

In conclusion, Intensive Neuromotor Therapy improved gross motor abilities of children with CP (0.00-15.18\% of GMFM scores), and this effect was higher in the initials modules, with continuous improving in all followed modules. Considering the five dimensions of GMFM, the largest gains were those related to the lying and rolling posture and sitting posture. This fact occurred because the majority of the studied children have severe motor impairments.

\section{Acknowledgments: \\ Vitória Research Centre and your multiprofessional team; University Centre Campos de Andrade; Children and families}

Conflict of interests:

Nothing to declare.

Funding:

Nothing to declare.

\section{REFERENCES}

Ahl, L. E., Johansson, E., Granat, T., \& Carlberg, E. B. (2005). Functional therapy for children with cerebral palsy: an ecological approach. Developmental Medicine \& Child Neurology, 47(9), 613-619.

Alagesan, J., \& Shetty, A. (2011). Effect of modified suit therapy in spastic diplegic cerebral palsy-a single blinded randomized controlled trial. Online Journal of Health and Allied Sciences, 9(4).1-3

Bailes, A. F., Greve, K., Burch, C. K., Reder, R., Lin, L., \& Huth, M. M. (2011). The effect of suit wear during an intensive therapy program in children with cerebral palsy. Pediatric Physical Therapy, 23(2), 136-142.

Bailes, A. F., Greve, K., \& Schmitt, L. C. (2010). Changes in two children with cerebral palsy after intensive suit therapy: a case report. Pediatric Physical Therapy, 22(1), 76-85.

Bailes, P., Greve, K., Burch, C., Reder, R., \& Huth, M. (2008). Effect of wearing the TherasuitTM during an intensive therapy program in children with cerebral palsy. Developmental Medicine \& Child Neurology 2008, 50(Suppl. 4), 1-41.

Bar-Haim, S., Harries, N., Belokopytov, M., Frank, A., Copeliovitch, L., Kaplanski, J., \& Lahat, E. (2006). Comparison of efficacy of Adeli suit and neurodevelopmental treatments in children with cerebral palsy. Developmental Medicine \& Child Neurology, 48(5), 325-330.

Blauw-Hospers, C. H., \& Hadders-Algra, M. (2005). A systematic review of the effects of early intervention on motor development. Developmental medicine \& child neurology, 47(06), 421-432.

Bower, E., McLellan, D. L., Arney, J., \& Campbell, M. J. (1996). A randomised controlled trial of different intensities of physiotherapy and different goal-setting procedures in 44 children 
with cerebral palsy. Dev Med Child Neurol, 38(3), 226-237.

Brasileiro, I. d. C., \& Moreira, T. M. M. (2008). Prevalência de alterações funcionais corpóreas em crianças com paralisia cerebral, Fortaleza, Ceará, 2006. Acta fisiátrica, 15(1), 37-41.

Carr, P. M., Kolobe, T. A., O'Connell, L., \& Sammy, W. (2006). Effects of an intensive therapy protocol on children with cerebral palsy. Paper presented at the Abstracts for the 2006 Combined Sections Meeting

Castilho-Weinert, L. V., \& Neves, E. B. (2016). Use of dynamic clothes in cerebral palsy rehabilitation: systematic review. ConScientiae Saúde., 15(2), 297303. doi: 10.5585/ConsSaude.v15n2.6224

Christiansen, A. S., \& Lange, C. (2008). Intermittent versus continuous physiotherapy in children with cerebral palsy. Developmental Medicine \& Child Neurology, 50(4), 290-293. doi: 10.1111/j.14698749.2008.02036.xDMCN02036 [pii]

Christy, J. B., Saleem, N., Turner, P. H., \& Wilson, J. (2010). Parent and therapist perceptions of an intense model of physical therapy. Pediatric Physical Therapy, 22 (2), 207-213.

Damiano, D., Quinlivan, J., Owen, B., Shaffrey, M., \& Abel, M. (2001). Spasticity versus strength in cerebral palsy: relationships among involuntary resistance, voluntary torque, and motor function. European journal of neurology, 8, 40-49.

Damiano, D. L. (2006). Activity, activity, activity: rethinking our physical therapy approach to cerebral palsy. Physical Therapy, 86(11), 15341540.

Damiano, D. L. (2009). Rehabilitative therapies in cerebral palsy: the good, the not as good, and the possible. Journal of child neurology, 24(9), 12001204.

DeLuca, S. C., Case-Smith, J., Stevenson, R., \& Ramey, S. L. (2012). Constraint-induced movement therapy (CIMT) for young children with cerebral palsy: Effects of therapeutic dosage. Journal of Pediatric Rehabilitation Medicine, 5(2), 133-142.

Dilenno, M., \& Atkinson, H. (2006). Quality of life, strength and function following an intensive strengthening program in a 17 year with cerebral palsy. Paper presented at the Abstracts for the 2006 Combined Sections Meeting.

Eek, M. N., \& Beckung, E. (2008). Walking ability is related to muscle strength in children with cerebral palsy. Gait \& posture, 28(3), 366-371.

Gannotti, M. E., Christy, J. B., Heathcock, J. C., \& Kolobe, T. H. (2014). A path model for evaluating dosing parameters for children with cerebral palsy. Physical Therapy, 94(3), 411-421.

Hanna, S. E., Bartlett, D. J., Rivard, L. M., \& Russell, D. J. (2008). Reference curves for the Gross Motor Function Measure: percentiles for clinical description and tracking over time among children with cerebral palsy. Physical therapy., 88(5), 596-607.

Hanna, S. E., Rosenbaum, P. L., Bartlett, D. J., Palisano, R. J., Walter, S. D., Avery, L., \& Russell, D. J.
(2009). Stability and decline in gross motor function among children and youth with cerebral palsy aged 2 to 21 years. Developmental Medicine $\mathcal{E}$ Child Neurology, 51 (4), 295-302.

Hwang, A.-W., Chao, M.-Y., \& Liu, S.-W. (2013). A randomized controlled trial of routines-based early intervention for children with or at risk for developmental delay. Research in developmental disabilities, 34(10), 3112-3123.

Krueger-Beck, E., Scheeren, E. M., Nogueira-Neto, G. N., Button, V. L. d. S. N., Neves, E. B., \& Nohama, P. (2011). Potencial de ação: do estímulo à adaptação neural. Fisioterapia em Movimento, 24(3), 535-547.

Martins, E., Cordovil, R., Oliveira, R., Letras, S., Lourenço, S., Pereira, I., . . Marques, M. (2015). Efficacy of suit therapy on functioning in children and adolescents with cerebral palsy: a systematic review and meta-analysis. Developmental Medicine $\mathcal{E}$ Child Neurology. 58(4), 348-360.

Morgan, C., Novak, I., Dale, R. C., Guzzetta, A., \& Badawi, N. (2014). GAME (Goals-Activity-Motor Enrichment): protocol of a single blind randomised controlled trial of motor training, parent education and environmental enrichment for infants at high risk of cerebral palsy. BMC neurology, 14(1), 1.

Myrhaug, H. T., Østensjø, S., Larun, L., OdgaardJensen, J., \& Jahnsen, R. (2014). Intensive training of motor function and functional skills among young children with cerebral palsy: a systematic review and meta-analysis. $B M C$ pediatrics, 14(1), 292.

Neves, E., Krueger, E., Rosário, B., Oliveira, M., Pol, S., \& Ripka, W. (2014). Fat Percentage Equation for Children with Cerebral Palsy: A Novel Approach. Paper presented at the XIII Mediterranean Conference on Medical and Biological Engineering and Computing 2013.

Neves, E. B. (2013). Trends in neuropediatric physical therapy. Frontiers in public health, 1(5).

Neves, E. B., Krueger, E., Stéphani de Pol, M. C., de Oliveira, N., Szinke, A. F., \& de Oliveira Rosário, M. (2013). Benefícios da Terapia Neuromotora Intensiva (TNMI) para o Controle do Tronco de Crianças com Paralisia Cerebral. Rev Neurocienc, 21, 549-555.

Neves, E. B., Scheeren, E. M., Chiarello, C. R., Costin, A., \& Mascarenhas, L. P. G. (2012). O PediaSuit ${ }^{\text {TM }}$ na reabilitação da diplegia espástica: um estudo de caso. Lecturas, Educación Física y Deportes-Buenos Aires, 166(15), 1-9.

Palisano, R. J., Hanna, S. E., Rosenbaum, P. L., Russell, D. J., Walter, S. D., Wood, E. P., . . G Galuppi, B. E. (2000). Validation of a model of gross motor function for children with cerebral palsy. Physical therapy, 80(10), 974-985.

Rosenbaum, P. L., Walter, S. D., Hanna, S. E., Palisano, R. J., Russell, D. J., Raina, P., . . G Galuppi, B. E. (2002). Prognosis for gross motor function in cerebral palsy: creation of motor development curves. Jama, 288(11), 1357-1363. 
Russell, D. J., Rosenbaum, P. L., Cadman, D. T., Gowland, C., Hardy, S., \& Jarvis, S. (1989). The gross motor function measure: a means to evaluate the effects of physical therapy. Developmental Medicine \& Child Neurology 31(3), 341-352.

Scheeren, E. M., Mascarenhas, L. P. G., Chiarello, C. R., Costin, A. C. M. S., Oliveira, L., \& Neves, E. B. (2012). Descrição do Protocolo PediaSuitTM. Fisioterapia em movimento, 25(3), 473-480.

Schiariti, V., Klassen, A. F., Cieza, A., Sauve, K., O'Donnell, M., Armstrong, R., \& Mâsse, L. C. (2014). Comparing contents of outcome measures in cerebral palsy using the international classification of functioning (ICF-CY): A systematic review. European Journal of Paediatric Neurology, 18(1), 1-12.

Schiariti, V., \& Mâsse, L. C. (2014). Identifying relevant areas of functioning in children and youth with Cerebral Palsy using the ICF-CY coding system: From whose perspective? European Journal of Paediatric Neurology, 18(5), 609-617.

Schiariti, V., Selb, M., Cieza, A., \& O'Donnell, M. (2015). International Classification of
Functioning, Disability and Health Core Sets for children and youth with cerebral palsy: a consensus meeting. Developmental Medicine \& Child Neurology, 57(2), 149-158.

Shvarkov, S. B., Davydov, O. S., Kuuz, R. A., Aipova, T. R., \& Vein, A. M. (1997). New approaches to the rehabilitation of patients with neurological movement defects. Neuroscience and Behavioral Physiology, 27(6), 644-647. doi: 10.1007/BF02461921

Sorsdahl, A. B., Moe-Nilssen, R., Kaale, H. K., Rieber, J., \& Strand, L. I. (2010). Change in basic motor abilities, quality of movement and everyday activities following intensive, goal-directed, activity-focused physiotherapy in a group setting for children with cerebral palsy. BMC Pediatr, 10, 26. doi: 10.1186/1471-2431-10-26 [pii]

Sposito, M. M. d. M., \& Riberto, M. (2010). Avaliação da funcionalidade da criança com Paralisia Cerebral espástica. Acta fisiátrica, 17(2), 50-61

Unay, B., Sarici, S., Vurucu, S., İnanç, N., Akin, R., \& Gokcay, E. (2003). Evaluation of bone mineral density in children with cerebral palsy. Turkish Journal of Pediatrics, 45(1), 11-14.

All content of Journal Motricidade is licensed under Creative Commons, except when otherwise specified and in content retrieved from other bibliographic sources. 